\title{
A matemática além dos muros da escola: construindo tabelas e gráficos sobre os fatores de saúde
}

\section{Mathematics beyond school walls: building tables and graphs about health factors}

\author{
Mateus Souza de Oliveira ${ }^{1}$
}

Alex Andrade Alves ${ }^{2}$

\begin{abstract}
Resumo: Este texto trata-se do relato de uma experiência realizada na disciplina de Matemática com as turmas do terceiro ano do Ensino Médio de uma escola do sudoeste baiano. O objetivo do trabalho foi desenvolver estratégias e ações que possibilitem aos educandos a construção, a análise e a interpretação de gráficos e tabelas em questões transversais mediante pesquisa de campo em suas comunidades. A proposta educativa contou com a participação de 75 educandos que foram a campos e coletaram dados de 2727 sujeitos. Foram abordados o tema transversal saúde e os conceitos básicos de Estatística. A experiência permitiu aplicar orientações para atividades práticas que revelaram avanços e limites para realização das atividades propostas.
\end{abstract}

Palavras-chave: Matemática; Saúde; Estatística.

\begin{abstract}
This text is an account of an experience conducted in the discipline of Mathematics with the classes of the third year of high school. The objective of this work was to develop strategies and actions that allow students to construct, analyze and interpret graphs and tables, in cross-cutting issues through field research in their communities. The educational proposal was attended by 75 students who went to the fields and collected data from 2727 subjects. The transverse health theme and the basic concepts of Statistics were addressed. The experience allowed us to apply guidelines for practical activities that revealed advances and limits to the accomplishment of the proposed activities.
\end{abstract}

Keywords: Mathematics; Cheers; Statistic.

\section{Introdução}

Os livros, principalmente os de Matemática, sempre exibem tabelas e gráficos, além dessas representações simbólicas estarem presentes também em outros materiais informativos, como por exemplo, jornais, revistas e internet. Essas ferramentas apresentam uma linguagem universal objetivando transmitir uma visão rápida do que está sendo

\footnotetext{
${ }^{1}$ Professor de Matemática do Instituto Federal da Bahia (IFBA) Mestre em Educação Matemática -UESCBahia - Brasil, matheusmathica@gmail.com

2 Professor de Matemática do Instituto Federal da Bahia (IFBA).Doutor em Educação pela Pontifícia Universidade Católica do Rio de Janeiro (PUC-Rio), Bahia, Brasil, alex.andrade.alves@gmail.com

Tangram - Revista de Educação Matemática, Dourados - MS - v.3 n.1, pp. 98-111 (2020)
} 


\section{A matemática além dos muros da escola: construindo tabelas e gráficos sobre os fatores de saúde}

investigado. Neste contexto, é de suma importância saber ler e interpretar os dados e as informações neles contidas.

Embora as tabelas e os gráficos sejam apresentados durante o Ensino Básico mediante a disciplina de Matemática, especificamente, quando os educadores abordam as noções básicas de Estatística ou até mesmo ou por meio de outras disciplinas, podemos notar que muitos educandos terminam o Ensino Médio sem ter uma noção do que representa cada dado ali contido. Isto mostra que este tipo de educando não consegue relacionar os conhecimentos matemáticos às situações cotidianas.

No decorrer das práticas educativas, podem ser vistas as dificuldades que os educandos têm em relacionar as abordagens estatísticas com os acontecimentos diários, principalmente, em transformar informações em dados numéricos. Estes fatores necessitam ser abordados com novos métodos de ensino que possibilitem ao educando a compreensão dessas transformações que geram certa confiabilidade. É importante destacar que alguns autores compreendem a Estatística como uma disciplina independente da Matemática. No entanto, o ensino de Estatística está incluído nas ementas dos conteúdos de Matemática no Ensino Básico, assim, não existe neste relato diferenças entre as mesmas.

Além disso, o ensino de qualquer disciplina é um processo complexo que necessita acontecer de forma transversal, ou seja, cruzando vários conteúdos. A saúde, por exemplo, constitui um dos temas transversais propostos nos Parâmetros Curriculares Nacionais (PCN) e reflete a preocupação com a qualidade de vida do corpo humano tanto de forma individual como coletiva. Por outro lado, o PCN + Ensino Médio (PCNEM) elucida a competência da contextualização sociocultural como forma de aproximar o educando da realidade e fazê-lo vivenciar situações que possibilitem reconhecer a diversidade que está a sua volta e reconhecer-se como indivíduo capaz de ler e atuar neste cenário.

D’Ambrosio (1986) enfatiza que a matemática possibilita uma análise crítica sobre seu papel na melhoria da qualidade de vida das pessoas, com diversas interpretações sobre o que representa a ciência para o bem-estar do ser humano. Já Cazorla et. al. (2017) sinaliza a importância de trabalhar com projetos em sala de aula a partir do levantamento de temas vivenciados pelos alunos. Esses pressupostos geram algumas inquietações, entre as quais destaco a criação de propostas de trabalhos que busquem propor atividades que possibilitem Tangram - Revista de Educação Matemática, Dourados - MS - v.3 n.1, pp. 98-111 (2020) 


\section{A matemática além dos muros da escola: construindo tabelas e gráficos sobre os fatores de saúde}

a construção do conhecimento matemático com uso de temas transversais para a contextualização das temáticas estudadas em sala de aula, partindo da ideia de que o educando pode aprender os conhecimentos formais além dos muros das escolas.

$\mathrm{O}$ atual relato tem como objetivo central descrever as estratégias e ações que possibilitam aos educandos a construção, a análise e a interpretação de gráficos e tabelas, em questões transversais mediante a pesquisa de campo em suas comunidades. Além disso, busca promover contribuições para integração do educando na comunidade; ressaltar o reconhecimento das inter-relações entre um ramo da Matemática com a área da saúde; e proporcionar aos educandos uma visão prática e teórica sobre a coleta e transformações dos dados por meio da pesquisa de campo.

Em meio a este contexto, o presente relato mostra-se relevante, pois apresenta, primeiramente, uma visão renovadora ao unir os conhecimentos adquiridos ambiente de sala de aula com o ambiente natural do educando; segundo, demonstra uma valorização do tema transversal saúde, haja vista que busca proporcionar o levantamento de dados estatísticos sobre os fatores de riscos da saúde humana nas comunidades; E, por fim, descreve a participação ativa dos educandos no processo de aprendizagem, mediante o desenvolvimento de competências e habilidades para a construção das atividades extraclasse, bem como as condições de realizar uma leitura global e compreensiva das tabelas e gráficos.

\section{Metodologia}

Trata-se de um relato de experiência das atividades desenvolvidas durante a primeira unidade da disciplina de Matemática com alunos do terceiro ano do turno matutino, pertencentes ao Ensino Médio de um colégio estadual situada no sudoeste da Bahia.

Eram duas turmas denominadas de $3^{\circ} \mathrm{A}$ e $3^{\circ} \mathrm{B}$ com, respectivamente, 37 e 38 educandos matriculados. Como um dos parâmetros era investigar a própria comunidade que residem, os grupos foram divididos em uma quantidade diferenciada. Deste modo, os educandos poderiam formar um grupo com um mínimo de seis e máximo de oito 


\section{A matemática além dos muros da escola: construindo tabelas e gráficos sobre os fatores de saúde}

componentes. Assim, foram formalizados cinco grupos em cada turma, a saber: A1, A2, A3, A4, A5, B1, B2, B3, B4 e B5.

A proposta educativa foi executada ao longo dos meses de abril e maio de 2018, em três etapas, a saber: a) Discussão do tema transversal: Saúde; b) Cadastramento da comunidade; e c) Transformando dados em informações. Para evitar um excesso de informações, nessa última etapa, são apresentados somente os recortes das construções realizadas pelo grupo, selecionado pelo motivo de apresentar a maior frequência acumulada em relação aos demais grupos.

Como se trata de um relato de experiência, não coexistiu a aplicação do Termo de Consentimento Livre e Esclarecido. Todavia, não será divulgado nenhum dado que possibilite identificar o colégio ou os educandos, respeitando o que é preconizado pela Resolução 466/12 do Conselho Nacional de Ética em Pesquisa (CONEP).

\section{Trajetória da proposta educativa: além dos muros da escola}

Esta seção se destina à trajetória da proposta educativa mostrando como aconteceu a introdução do tema transversal saúde e as orientações importantes para o preenchimento das fichas de cadastramento, as quais são utilizadas por todos os programas e políticas aqui citados.

\section{Discussão do tema transversal: Saúde}

O ensino de Matemática relacionado com tema o Saúde tem sido um desafio para alguns educadores, principalmente no que se refere à possibilidade de correlacionar essa área do conhecimento de forma que contribua para uma aprendizagem efetiva e transformadora.

“Como a Estatística é parte do método científico, é natural que o trabalho com a mesma parta de problemas de outras áreas do conhecimento e das práticas sociais, viabilizando a interdisciplinaridade e a inserção de temas transversais." (Cazorla et. al. 2017, p. 17). Dessa forma, considerando que esse conhecimento está incluso nos conteúdos do componente curricular de Matemática para o terceiro ano do ensino, durante o planejamento anual, elaborei uma proposta educativa que estava além dos muros da escola.

Tangram - Revista de Educação Matemática, Dourados - MS - v.3 n.1, pp. 98-111 (2020) 


\section{A matemática além dos muros da escola: construindo tabelas e gráficos sobre os fatores de saúde}

Com intuito de transformar essa proposta em realidade, tracei um cronograma com quatro semanas de aula. Cabe ressaltar que a disciplina de Matemática tem uma carga horária semanal de três horas/aulas e em ambas as turmas havia uma aula nas quintas e duas nas sextas-feiras.

Durante a primeira semana, especificamente na aula de quinta-feira, apresentei uma exposição dos sintomas investigados por um Agente Comunitário de Saúde (ACS). Neste contexto, foram discutidos pelos educandos os seguintes casos de promoção de saúde que estes profissionais acompanham: Hipertensão Arterial, Diabetes e Sedentarismo.

Além disso, apresentei às turmas a importância da Carta de Ottawa (1986) que sinaliza os cuidados primários em saúde. Segundo a mesma,

Promoção da saúde é o nome dado ao processo de capacitação da comunidade para atuar na melhoria de sua qualidade de vida e saúde, incluindo uma maior participação no controle deste processo. Para atingir um estado de completo bem-estar físico, mental e social os indivíduos e grupos devem saber identificar aspirações, satisfazer necessidades e modificar favoravelmente o meio ambiente. A saúde deve ser vista como um recurso para a vida, e não como objetivo de viver. Nesse sentido, a saúde é um conceito positivo, que enfatiza os recursos sociais e pessoais, bem como as capacidades físicas. Assim, a promoção da saúde não é responsabilidade exclusiva do setor saúde, e vai para além de um estilo de vida saudável, na direção de um bem-estar global. (Brasil, 2002, p.9)

Por fim, foi solicitada uma pesquisa individual para a qual cada educando deveria pesquisar sobre as causas e as prevenções de pessoas que são hipertensos, diabéticos, fumantes, alcoólatras e sedentárias, além de enfatizar a importância da atividade física para estes sujeitos.

\section{Cadastramento da comunidade}

Nesta etapa, busquei proporcionar aos educandos uma aprendizagem global, enfatizando a importância de quantificar os conhecimentos sobre os temas pesquisados dentro dos ambientes em que eles vivem. Assim, na segunda aula apresentei uma ficha de cadastramento que os educandos iriam preencher durante uma investigação sobre a saúde de suas respectivas comunidades.

Logo abaixo, apresento a ficha de cadastramento utilizada nesta proposta educativa seguida de uma descrição minuciosa de parte dela.

Tangram - Revista de Educação Matemática, Dourados - MS - v.3 n.1, pp. 98 -111 (2020) 


\section{A matemática além dos muros da escola: construindo tabelas e gráficos sobre os fatores de saúde}

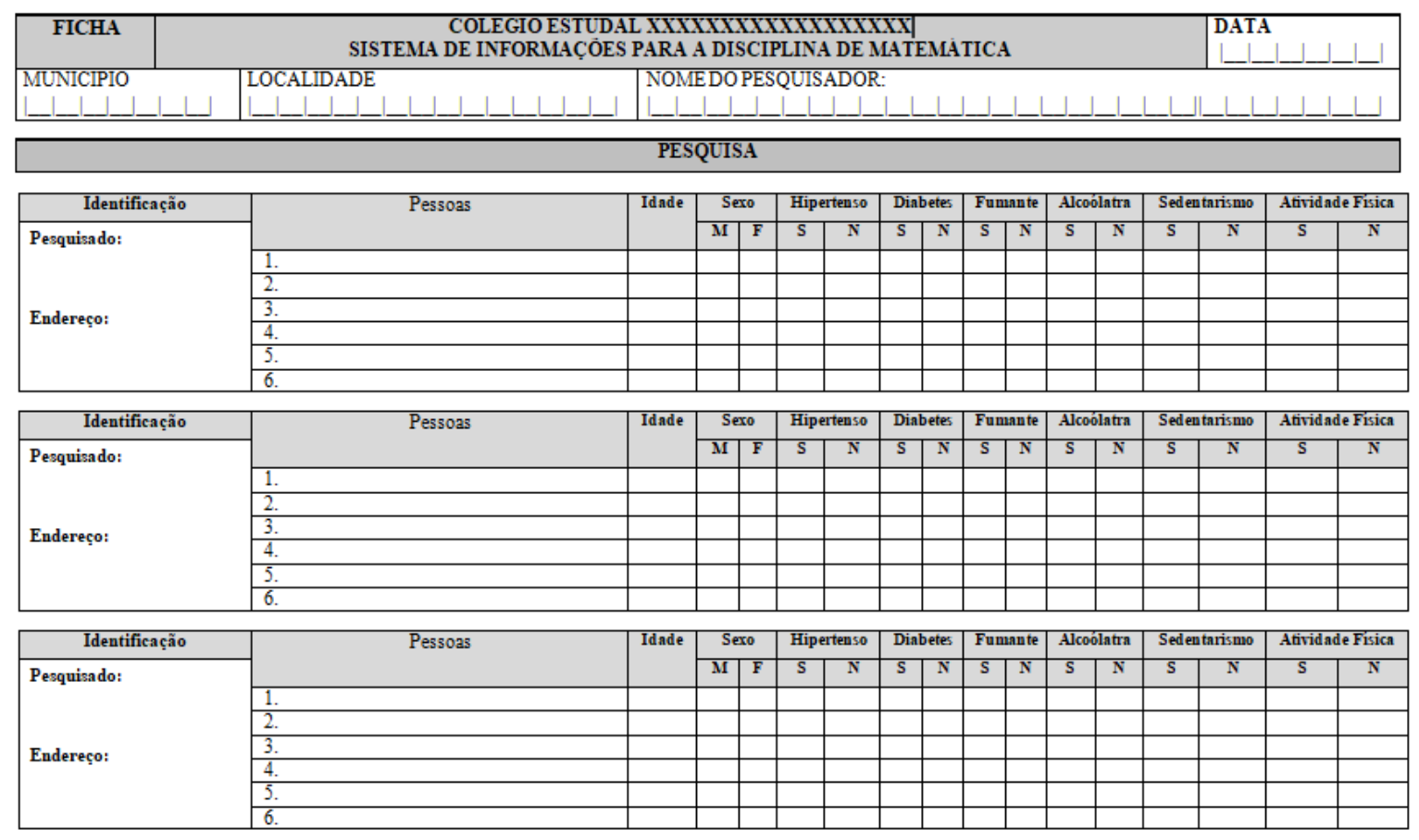

Figura 1: Ficha de Cadastramento Autor: Própria

$\mathrm{Na}$ ficha de cadastramento, temos na primeira barra na linha superior, de forma centralizada, o nome completo do colégio estadual e, logo abaixo, o título da proposta “SISTEMA DE INFORMAÇÕES PARA A DISCIPLINA DE MATEMÁTICA”. No lado esquerdo, o nome ficha e direito a "DATA". E na parte inferior da barra, na forma sequencial, a opção de descrever o "MUNICÍPIO", "LOCALIDADE" e o "NOME DO PESQUISADOR".

É importante enfatizar que os educandos foram divididos em duplas e cada um deles iria entrevistar o seu parceiro. Nesse momento, surgiram diversas dúvidas e equívocos no preenchimento da primeira barra, entre os quais destacam-se as dificuldades de colocar cada caractere em seu espaço correto. Esse fato mostrou que a grande maioria não estava familiarizada com inscrição de dados manuais.

A segunda barra da ficha era composta com o nome "PESQUISA" e as outras três barras eram idênticas, com a seguinte divisão: do lado esquerdo, uma coluna de "Identificação", local destinado a identificação do pesquisado e o enderenço do mesmo. Em

Tangram - Revista de Educação Matemática, Dourados - MS - v.3 n.1, pp. 98-111 (2020) 


\section{A matemática além dos muros da escola: construindo tabelas e gráficos sobre os fatores de saúde}

seguida, vinham três colunas intituladas de "Pessoas", "Idade" e "Sexo" divididas em seis linhas com os espaços para colocar os nomes dos residentes daquele domicílio e suas respectivas idades, bem como sinalizar com um $\mathrm{X}$ na letra $\mathrm{M}$ se fosse do sexo masculino ou na letra $\mathrm{F}$ se fosse do feminino.

Do centro em diante essa barra foi composta por seis colunas, identificadas, respectivamente, de "Hipertenso", "Diabetes", "Fumante", "Alcoólatra", "Sedentarismo" e "Atividade Física". Cada uma delas era subdividida em duas colunas onde era preciso sinalizar com um $\mathrm{X}$ na letra $\mathrm{S}$ se o residente citado na pesquisa apresentava a suposta identificação e caso negativo a sinalização tinha que ser feita na letra N.

A única dúvida durante esse momento foi em relação à quantidade de moradores nas residências que poderia ser superior a seis moradores. Assim, os educandos foram orientados a utilizar a próxima barra sinalizando que era continuação da(s) barra(s) anterior(es). Antes do final da aula, dividi os grupos e ressaltei que a partir daquele momento eles poderiam já se organizarem para fazer a pesquisa fora dos muros da escola, no turno vespertino ou nos dias não letivos.

Foram ressaltadas algumas cautelas como, por exemplo, que a pesquisa não poderia ser feita após o pôr do sol e nem muito menos no intervalo das 11:30 às 13:30. Além disso, nenhum educando poderia fazer o cadastramento de forma solitária ou em duplas, logo as visitas domiciliares só poderiam ser realizadas se estivessem presentes mais de três componentes do grupo e cada um deveria ter o consentimento do seu respectivo responsável para visitar cada residência da sua comunidade.

É importante salientar que os educandos também foram informados sabre a importância de saber entrar em contato com os investigados, ou seja, todos foram orientados primeiramente, a cumprimentar com uma saudação (Olá, boa tarde!), se identificar como alunos do colégio, em seguida, sinalizar o motivo da pesquisa e, após o preenchimento da ficha, agradecer pela colaboração.

\section{Transformando dados em informações}

De acordo com (Cazorla et. al. 2017, p. 16), “A inserção da Estatística por meio do bloco Tratamento da Informação merece um destaque especial, uma vez que por sua própria Tangram - Revista de Educação Matemática, Dourados - MS - v.3 n.1, pp. 98-111 (2020) 


\section{A matemática além dos muros da escola: construindo tabelas e gráficos sobre os fatores de saúde}

natureza a Estatística possibilita trabalhar a Matemática com as outras áreas do conhecimento e com os Temas Transversais." Partindo de tal pressuposto, esta etapa da pesquisa descreve a concretização dessa possibilidade mediante os resultados obtidos pelos educandos.

Além disso, os Parâmetros Curriculares Nacionais (PCN) destacam a importância do conteúdo "Tratamento da Informação", pontuando que essa abordagem tem que estimular os educandos na possibilidade de fazer perguntas, estabelecer relações entre os números e o significado das informações obtidas por intermédio dos meios de comunicação, construir análises e justificativas, como também desenvolver o espírito de investigação.

Assim, durante as próximas seis aulas foram abordados os conceitos de amostra, população, variáveis estatísticas, dados brutos, rol, amplitude, frequência absoluta, frequência acumulada e frequência relativa, bem como a maneira de transformar esses dados nos principais tipos de gráficos, demonstrando na prática como se constrói e interpreta cada situação explorada.

Cabe ressaltar que os educandos apresentaram um interesse maior para esses conceitos, principalmente quando os dados brutos eram organizados em rol e consequentemente geravam facilmente as tendências dos comportamentos das populações exploradas. Nesse momento, existiam também algumas interações entre todos os sujeitos da sala de aula quando um educando relatava suas experiências no seu campo de pesquisa e sinalizam as tendências encontradas em sua comunidade.

Durante as aulas, os educandos foram orientados a adotarem as seguintes faixas etárias na pesquisa: jovens (de 0 a 19 anos), adultos (de 20 a 59 anos) e idosos (acima de 60 anos). Em síntese, foram pesquisados 832 jovens, 1501 adultos e 394 idosos, isto gera um total de 2727 sujeitos.

Segundo Pereira (2009), as tabelas são usadas para sintetizar um conjunto de informações importantes, e os gráficos, além de resumirem as informações, apresentam um efeito visual que prende a atenção dos leitores tornando-se mais interessante o estudo do fenômeno abordado. Neste sentido, apresento logo abaixo as construções da tabela e dos gráficos realizadas pelo Grupo A5.

Tangram - Revista de Educação Matemática, Dourados - MS - v.3 n.1, pp. 98-111 (2020) 


\section{A matemática além dos muros da escola: construindo tabelas e gráficos sobre os fatores de saúde}

Tabela 1: Distribuição de Frequências Etárias da Comunidade

\begin{tabular}{|c|c|c|c|c|c|}
\hline Faixa Etária & Masculino & Feminino & $\begin{array}{c}\text { Frequência } \\
\text { Absoluta }\end{array}$ & $\begin{array}{c}\text { Frequência } \\
\text { Acumulada }\end{array}$ & $\begin{array}{c}\text { Frequência } \\
\text { Relativa }\end{array}$ \\
\hline Jovens & $\mathbf{5 0}$ & $\mathbf{5 2}$ & $\mathbf{1 0 2}$ & $\mathbf{1 0 2}$ & $\mathbf{2 3 , 3 9 \%}$ \\
\hline Adultos & $\mathbf{1 3 7}$ & $\mathbf{1 3 8}$ & $\mathbf{2 7 5}$ & $\mathbf{3 7 7}$ & $\mathbf{6 3 , 0 7 \%}$ \\
\hline Idosos & $\mathbf{3 8}$ & $\mathbf{2 1}$ & $\mathbf{5 9}$ & $\mathbf{4 3 6}$ & $\mathbf{1 3 , 5 3 \%}$ \\
\hline
\end{tabular}

Autor: Grupo A5/2018

A Tabela 1 foca na distribuição de frequências etárias da comunidade, a partir da qual o grupo A5 relata que sua comunidade é composta por uma maior de pessoas classificadas como adultos, seguidos por quantidade de jovens e uma minoria de idosos. Essa afirmação mostra que os educandos souberam analisar e interpretar a tabela coerentemente.

Esse modelo de tabela foi um padrão desenvolvido durante as aulas, no qual caberia aos grupos organizar os dados de acordo as suas descrições e, em seguida, encontrar matematicamente as frequências solicitadas. De forma análoga, foram padronizados os modelos gráficos que só exigiram dos educandos organização dos dados de acordo a cada descrição e sinalização das interpretações gráfica encontrada.

Essa padronização só aconteceu, porque os educandos não tinham noções básicas de informática. Vale ressaltar que o ambiente escolar não apresenta um laboratório de informática e não existe nenhuma componente curricular que minimiza esta dificuldade na programação do Ensino Médio deste local.

Gráfico 1: Representação Visual do Gênero

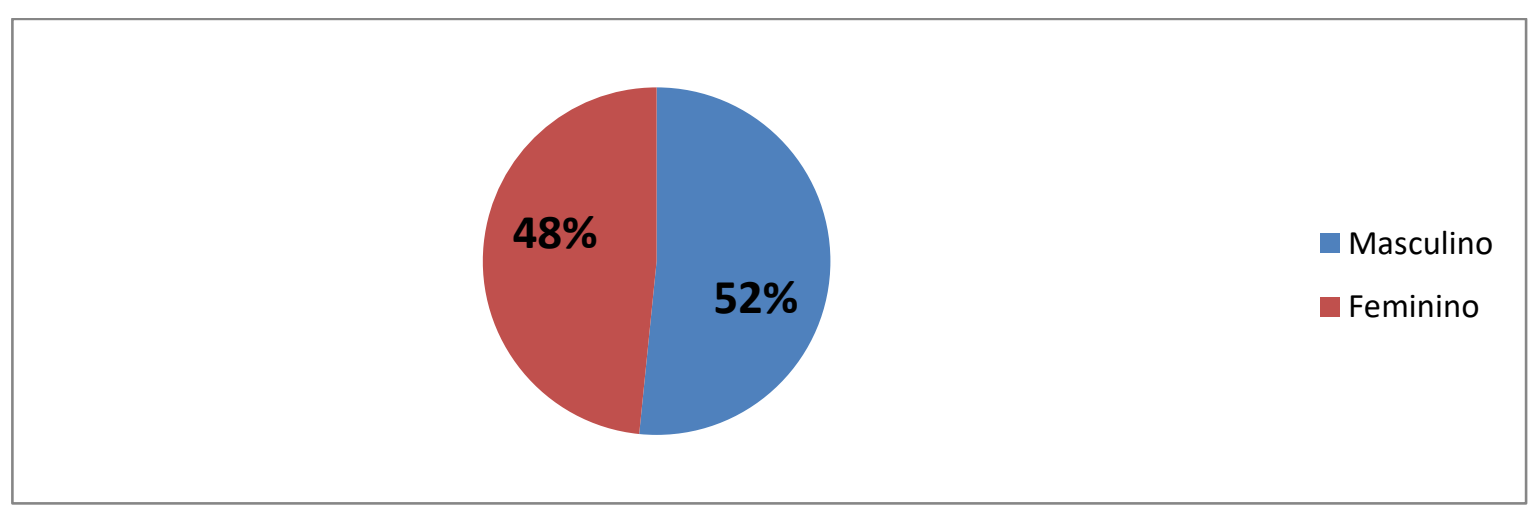

Autor: Grupo A5/2018

Tangram - Revista de Educação Matemática, Dourados - MS - v.3 n.1, pp. 98-111 (2020) 


\section{A matemática além dos muros da escola: construindo tabelas e gráficos sobre os fatores de saúde}

O gráfico 1 do tipo pizza ou setores, foi selecionado para representar a visibilidade do gênero da comunidade pesquisada. Nessa ótica, o grupo A5, informou que sua comunidade tem uma quantidade superior de pessoas do sexo masculino em relação ao sexo feminino. Essa colocação mostra que a análise e interpretação do gráfico ocorre de forma coerente.

Gráfico 2: Representação Visual da Faixa Etária

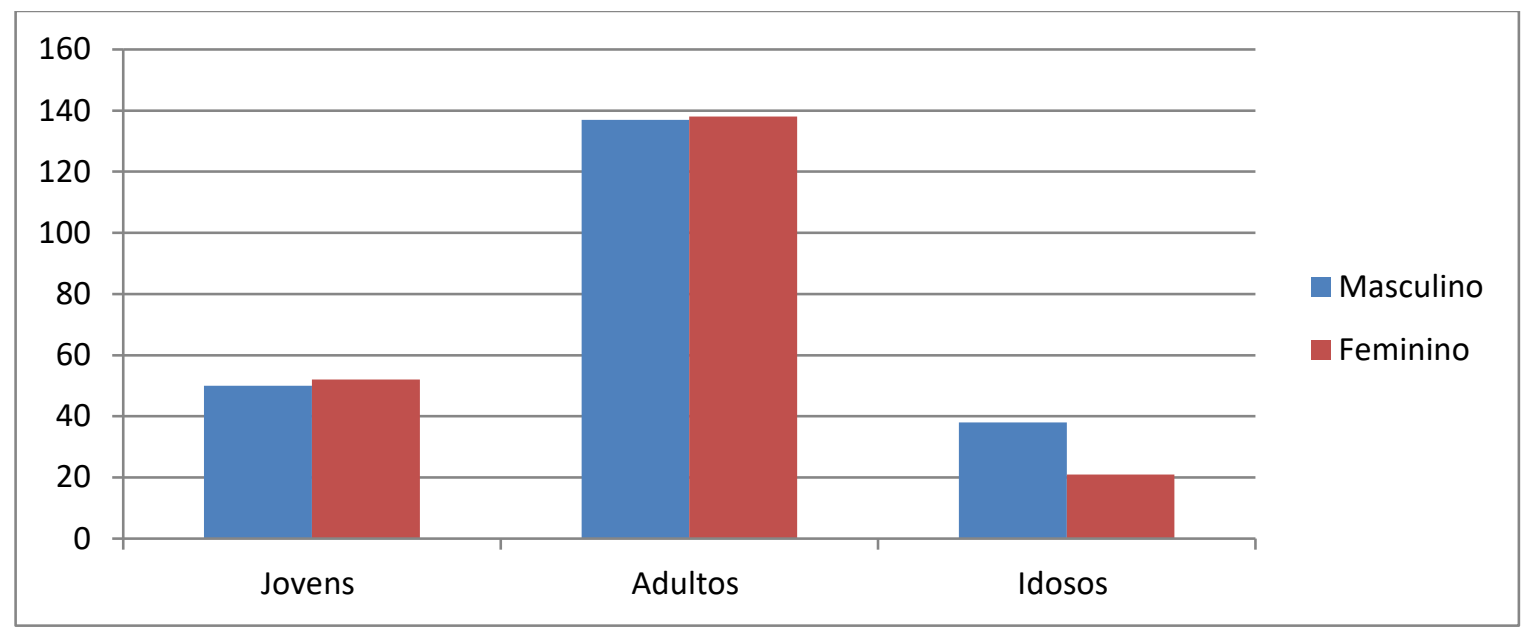

Autor: Grupo A5/2018

O gráfico 2 do tipo colunas foi selecionado para representar a faixa etária da comunidade investigada. Deste modo, o grupo A5 relatou que sua comunidade se concentra em uma faixa etária composta por adultos e ressalta que nas próximas décadas a quantidade de mulheres será superior ao dos homens. Essa afirmação mostra uma evolução nos conhecimentos adquiridos pelos educandos, pois não só analisa e interpreta corretamente o gráfico como faz estimativas coerentes.

Gráfico 3: Representação Visual das Doenças Crônicas por Faixa Etária

Tangram - Revista de Educação Matemática, Dourados - MS - v.3 n.1, pp. 98-111 (2020) 


\section{A matemática além dos muros da escola: construindo tabelas e gráficos sobre os fatores de saúde}

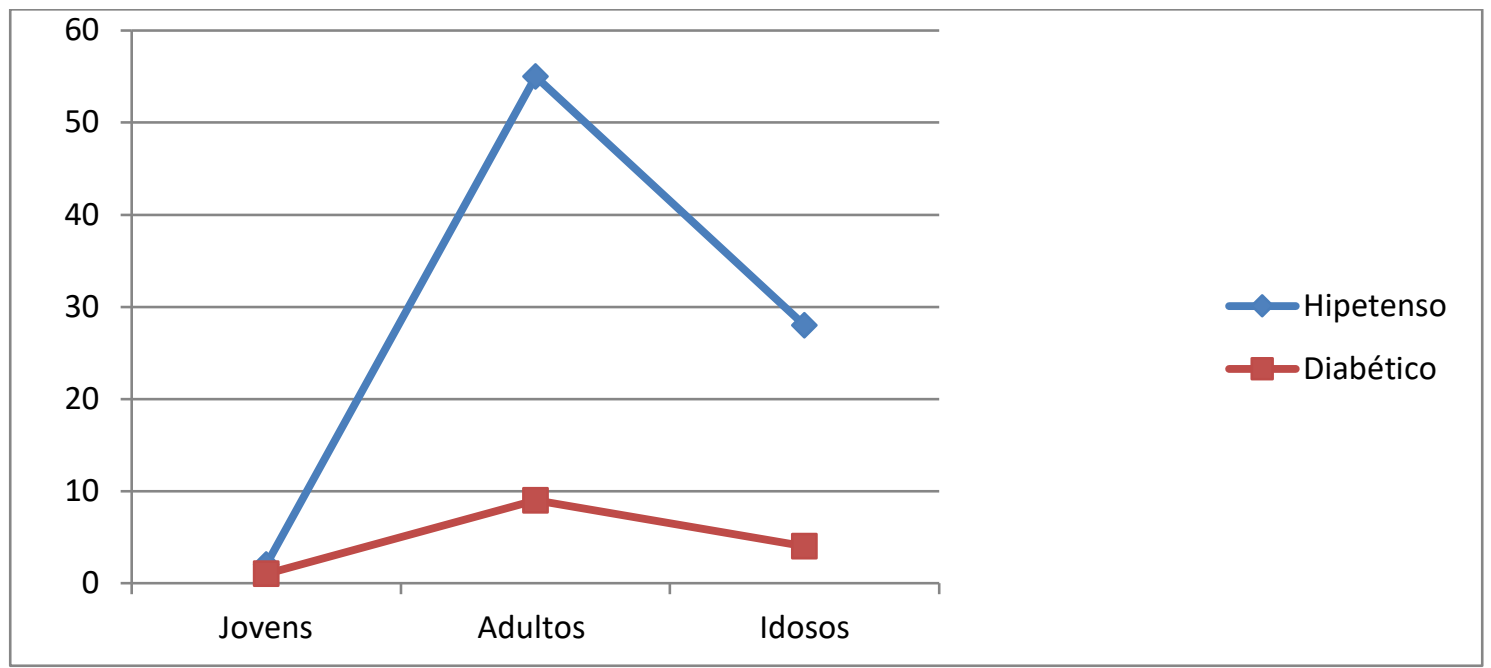

Autor: Grupo A5/2018

O gráfico 3 do tipo gráfico em linhas, foi selecionado para representar dois tipos de doenças crônicas presentes na comunidade com relação a faixa etária. Assim, o grupo A5 relatou que os adultos estão mais vulneráveis a esses tipos de doenças e ressaltou a necessidade de uma prevenção para os eles. Essa argumentação demostra não só uma análise e interpretação coerente do gráfico, como também a precisão de uma intervenção, entretanto o grupo poderia explorar também outras informações contidas nessa visualização, por exemplo, os casos de hipertensão são aproximadamente seis vezes maiores que os de diabéticos em relação às faixas etárias de adultos e idosos.

Gráfico 4: Representação Visual das Dependências Químicas por Faixa Etária

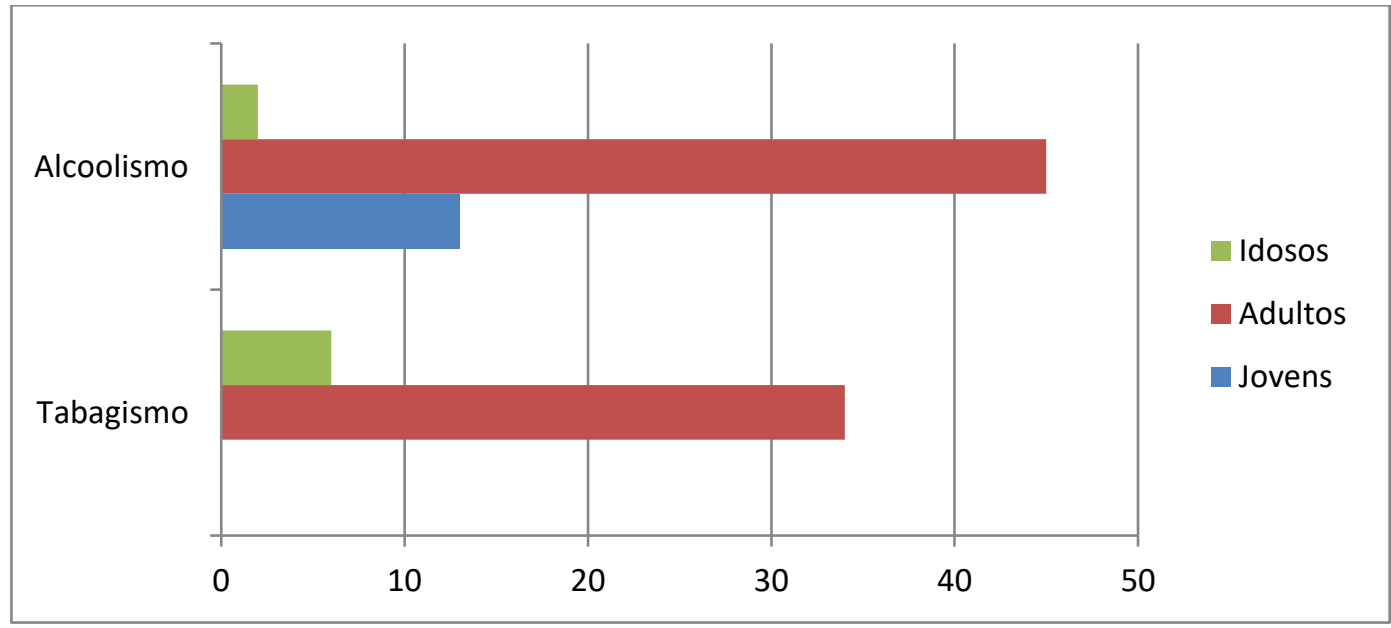

Autor: Grupo A5/2018

Tangram - Revista de Educação Matemática, Dourados - MS - v.3 n.1, pp. 98-111 (2020) 


\section{A matemática além dos muros da escola: construindo tabelas e gráficos sobre os fatores de saúde}

Esse gráfico 4 do tipo barra foi selecionado para representar dois tipos de dependências químicas com relação à faixa etária. Nesse sentido, o grupo A5 chegou a conclusão que os adultos são as classes mais vulneráveis à dependência do alcoolismo e do tabagismo, o que gera a necessidade de uma campanha de prevenção, além disso, informaram ainda que alguns jovens apresentam a vulnerabilidade à dependência do alcoolismo, sendo importante a conscientização desse classe para não serem dependentes também do tabagismo. Essas afirmações mostram um avanço coerente na análise e interpretação do gráfico 4.

Gráfico 5: Representação Visual da Saúde Física por Faixa Etária

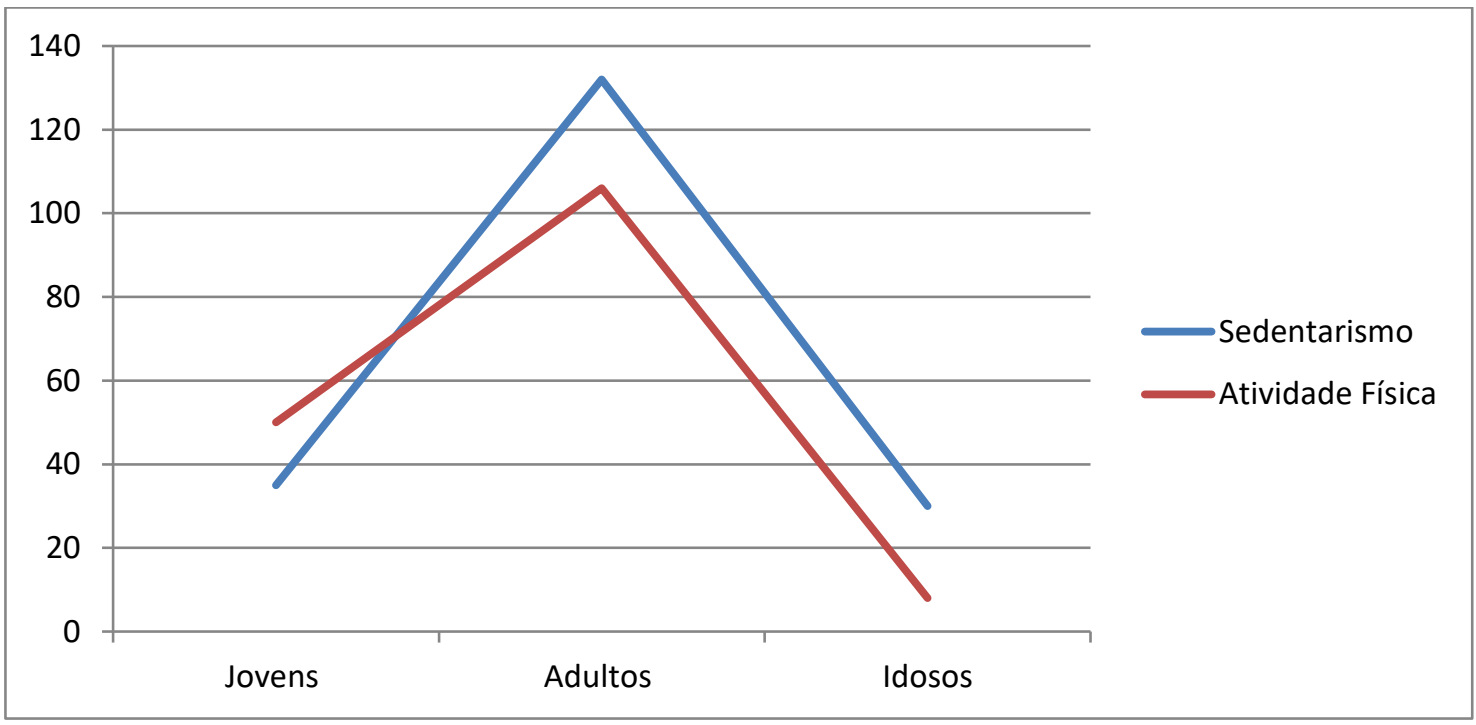

Autor: Grupo A5/2018

O gráfico 5 do tipo de linha foi selecionado para representar a saúde física da comunidade em relação a faixa etária. Deste modo, o grupo A5 descreve que o sedentarismo é algo predominante nos adultos e idosos e aponta a necessidade de uma campanha que incentive essas faixas etárias a realizarem práticas esportivas, além disso, solicita que esta campanha seja direcionada aos jovens também. Isto mostra que os educados conseguiram fazer uma análise e interpretação coerente do gráfico acima.

Para concluir essa proposta educativa, nas últimas aulas foram revistas algumas dúvidas sobre a entrega do relatório digitalizado com a construção da pesquisa que aponta Tangram - Revista de Educação Matemática, Dourados - MS - v.3 n.1, pp. 98-111 (2020) 


\section{A matemática além dos muros da escola: construindo tabelas e gráficos sobre os fatores de saúde}

as causas e as prevenções investigadas, seguidos da tabela e das construções gráficas e suas respectivas interpretações e no final uma breve conclusão sobre o que esta pesquisa diz sobre a comunidade pesquisada. Por fim, recebi até o término do expediente letivo, dia 25/05/2018, os relatórios de todos os grupos com todas as fichas de cadastramento preenchidas por eles como anexo.

\section{Considerações finais}

Inicialmente, ressalto a importância de mostrar as relações existentes entre o ensino de Matemática e todos os temas transversais, pois a proposta educativa possibilitou um novo olhar sobre os conteúdos de estatística, principalmente por proporcionar aos educandos uma experiência diferente daquelas habituadas no seu ambiente educacional.

Nesse percurso, foram observados alguns avanços e limites. Com o olhar sobre essa realidade, observei que os educandos conseguiram quantificar as informações colhidas em suas comunidades para construções de tabelas e gráficos, bem como analisar e interpretar essas ferramentas. Entretanto, a falta de conhecimentos sobre noções básicas de informática limitou a criatividade dos sujeitos. Nesta ótica, seria interessante a implantação de uma disciplina curricular que aborda os conhecimentos básicos de informática.

Considerando os resultados satisfatórios dessa experiência, é de suma importância que educadores matemáticos busquem sempre encontrar os melhores caminhos para o processo de ensino-aprendizagem em relação aos meios de abordagens dos conteúdos de Matemática em seus diversos níveis e modalidade de ensino. Vale lembrar que não existe um único caminho que possa ser identificado como o melhor para o sucesso educacional e, dessa forma, conhecer diversas possibilidades de trabalhar em sala de aula e fora dela é fundamental para que haja novas tendências de ensino.

Por fim, considerando os resultados satisfatórios alcançados com minha experiência em sala de aula, acredito que o ensino de Matemática deve ir além da simples transmissão de fórmulas aos educandos e partir de propostas metodológicas que dão sentido e importância aos conceitos matemáticos para a compreensão de situações da realidade dos educandos, transformando-os em sujeitos protagonistas na produção de conhecimento.

Tangram - Revista de Educação Matemática, Dourados - MS - v.3 n.1, pp. 98-111 (2020) 


\section{A matemática além dos muros da escola: construindo tabelas e gráficos sobre os fatores de saúde}

\section{Referências}

Brasil (1997, 1998, 1999, 2000, 2002, 2006) Ministério da Educação. Secretaria do Ensino Fundamental. Parâmetros curriculares nacionais: Matemática: MEC/SEF.

Brasil (2002) Ministério da Educação. PCN+ ensino médio: orientações educacionais complementares aos PCN - ciências da natureza, matemática e suas tecnologias. Brasília, MEC/Semtec.

Brasil (2002) Ministério da Saúde. Secretaria de Políticas de Saúde. Projeto Promoção da Saúde. As cartas da promoção da saúde/Ministério da saúde, secretaria de políticas de saúde, projeto promoção da saúde. Brasília: Ministério da Saúde.

Cazorla, I. M.; Magina, S. M. P.; Ferreira, V. G. G.; Guimarães, G. L. (org.).(2017) Estatística para os anos iniciais do ensino fundamental. Brasília: Sociedade Brasileira de Educação Matemática - SBEM. (Biblioteca do Educador, Coleção SBEM, 9, Ebook.)

D'ambrosio, Ubiratan.(1986) Da realidade a ação: reflexões sobre educação e matemática. São Paulo: Summus.

Pereira, S. (2009) A leitura e interpretação de tabelas e gráficos para alunos do $6^{\circ}$ ano do ensino fundamental: uma intervenção de ensino. 180 p. Dissertação (Mestrado Profissional em Ensino de Matemática), Pontifícia Universidade Católica de São Paulo, São Paulo.

Recebido:28/12/2019

Aprovado:20/03/2020

Tangram - Revista de Educação Matemática, Dourados - MS - v.3 n.1, pp. 98-111 (2020) 